\title{
Improved learning performance based on a flipped classroom concept - a case study
}

\author{
Dressler, Soeren ${ }^{\mathrm{a}}$ and Rachfall, Thomas ${ }^{\mathrm{b}}$ \\ ${ }^{\mathrm{a}}$ Director of Master in Business Adminsitration \& Engineering, Department for IT \& \\ Business Engineering, University of Applied Sciences Berlin, Germany, ${ }^{\mathrm{b}}$ Department for IT \\ \& Business Engineering, University of Applied Sciences Berlin, Germany.
}

\begin{abstract}
Aim of the research was to improve effectiveness of university education. With the use of new digital tools the learning processes in many different disciplines have been enhanced. However, the traditional class room training can hardly be replaced entirely as the students' motivation drops with less direct interaction with the instructor. Hence small private online courses are more successful than massive online education. The authors have developed a sophisticated flipped classroom learning approach incorporating various digital tools ranging from different kinds of videos to a class response system combined with class room lectures. The case of the course introduction to management accounting at the University of Applied Sciences Berlin is been presented to demonstrate the usefulness of the flipped classroom concept. An empirical analysis confirms that the students' acceptance is highest if various methods of teaching are been applied. In particular relying on digital tools only is seen as ineffective and of less value. Eventually, based on the analysis and classroom observations improvement opportunities have been derived in order to further increase the learning performance.
\end{abstract}

Keywords: Digital learning, flipped classroom, motivation, learning performance, class response systems, blended learning. 


\section{Introduction}

Study wherever and whenever you want! No more dependence on time and space. Every student can listen to top professors. MOOCs (massive open online courses) raised several expectations and during the last years MOOCs are one of the most common buzzwords in educational science. Everything started with the first MOOC introduced by the University of Manitoba in 2008. The breakthrough was in October 2012, when 180.000 students enrolled for the free edx.org course CS50x (a Harvard MOOC of Introduction to Computer sciences) and just one month later the New York Times announced "The year of the MOOC". However, less than 1\% (1.439) of the course participants received a certificate. Empirical findings on MOOC-participants indicate a drop-out rate of around $90 \%$ for almost all MOOCs (Schultz 2014). John Hennessy (president of Stanford University) named the problem and said "such courses were too large to engage and motivate most students successfully" (Hill and Waters 2014). As a consequence some of the MOOCproviders changed their views. Instead of "massive" the providers decreased the amount of participants. These new alternatives are called SPOCs (small private online courses) and they provide - because of their relatively small size - the possibility of an intensive dialog between student and lecturer.

As a result of this development some Universities support teachers with ideas around flipped classroom lectures. These hybrid-lectures include the classic frontal teaching combined with online content and ensure an active exchange and quick feedback. This shall increase the student motivation. A basic assumption is, that a professor in traditional courses often realizes weaknesses and gaps among students not until the exams. However, online feedback can be seen in real-time, if required already during the lecture. With this new approach, the professor is able to recognize weak students seeking for help. Another advantage of flipped classroom lectures is, that the student is still present in the classroom. A recent meta-study showed: as more present students are as significant better are their results (Schulmeister 2015).

This paper deals with the question if the mentioned considerations are adoptable for the course "introduction to managing accounting" at the Hochschule für Technik und Wirtschaft (HTW) University of Applied Sciences Berlin. More detailed the authors analyse student motivation depending on a flipped classroom concept.

\section{Student motivation and the new learning concept of the course: introduction to management accounting}

The influence of new media on the learning behavior is an often mentioned topic and scientists have analyzed it extensively during the last years. Under the influence of an increasing amount of students and the development of new technology, the learning behavior is - without a doubt - changing. Therefore this chapter introduces a short section 
about student motivation (2.1) as well as an introduction to the new concept and the used digital tools of the course: introduction to management accounting (2.2).

\subsection{Student motivation}

Every performance which exceeds the daily requirement of a student (routine decisions), request for abilities and effort. This basic assumption can be found in different models regarding learning performance (e.g. Heller 1991, Helmke and Weinert 1997 read in Rheinberg et al. 2001). According to Rheinberg et al. (2001) these models include 2 important factors: cognitive competence (e.g. intelligence, knowledge) and motivational factors (e.g. self-concept, instrumental motivation).

Another approach from Deci and Ryan (2000) identifies different types of motivation. They are based in the perceived locus of causality, which can be internal, external or impersonal. Thereby it is important to know, that the classical motivation psychology is interactionistic. The behavior of a person is therefore, a result of interactions between personal- and situational factors. These personal factors are known as motives and can be explained as attributes which lead to a preference of stimuli. Situational factors on the other hand describe the chance to reach the preferred stimuli in a specific situation. If situational factors fit with personal factors a current motivation can accrue. Only these current motivation (and not the motives) influence directly the behavior of a person and as a consequence increase the performance (Figure 1).

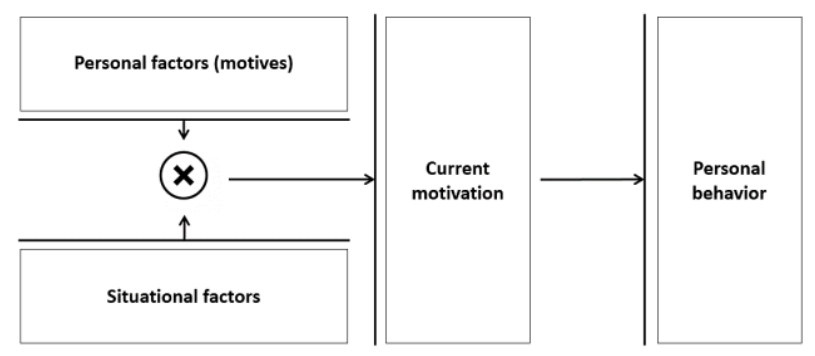

Figure 1. Classical model of motivation psychology. Source: based on Rheinberg et al. 2001

If these basic assumptions are adopted to an university classroom, there are two possibilities to influence students motivation: adjust the motives and offer stimuli.

\subsection{The flipped classroom concept of the course: introduction to management accounting}

The authors teach the course introduction to management accounting at the HTW Berlin University of Applied Sciences. Main content of the course are product costing methods, special cost analysis methods and budgeting methods. Furthermore relevant topics, recent developments and international aspects are discussed. The course consisted (before 
changing to the new concept) of around 50-60\% classical frontal teaching and 40-50\% exercises. The structure and content of the course reflected a typical German management accounting course (Dressler and Rachfall 2012). An analysis of the course statistics shows an average drop-out-ratio of $20 \%$ and an average grade of $3.0^{1}$ over the last 5 years. This average performance so far is creating a problem as business engineers often are employed in technical sales and large project accounting tasks in which proficient management accounting capabilities are required. There is a latent risks that graduates are not optimally educated for the job market requirements. Due to this and the relatively high drop-out-ratio the authors decided to develop the new concept.

To support the learning process of the students - without lowering the high level of the course - the authors changed from a classical lecture format to a flipped classroom design. Several different tools are part of the new concept:

Theory videos: To increase the effectivity of the lectures, 12 theory videos were produced. They cover the 12 most important lectures and are based on the original Power Point slides of the lectures. Each of the videos last for approximately 20 minutes and is uploaded in advance. So, every student has the opportunity to be well prepared for the lecture (e.g. structure first questions). Furthermore the students are able to learn at an individual pace and they can repeat the videos for as many times as they wish.

Presentations: Moreover, the Power Point slides of each lecture (\#14) are uploaded (as a PDF file). Every student can take notes, comments and questions.

Exercise videos: Additionally, 31 videos were produced with different exercises. These Excel based videos last for around 6 minutes each. On the basis of these videos it is possible to understand and reproduce the content and approach of the exercises.

Class response System (CRS): Following the students wish to provide more exercises, the authors introduced a CRS. The system selected and used is called ARSnova and is provided as an open source solution by the TH Mittelhessen. At the moment the students can find more than 90 exercises and questions which deal with the content of the lecture. ARSnova offers advantages for both, students and lecturers. The first can test their knowledge and practice and lecturers have due to ARSnova the possibility to monitor the level of knowledge. As a result weaknesses can be identified and eliminated. Consequently a target oriented knowledge transfer can be provided.

\footnotetext{
${ }^{1}$ A 3.0 can be translated as satisfactory - a performance which meets the average requirements. The corresponding equivalent would be $\mathrm{C}$.
} 
In combination, the different tools should create a continuous engagement of the students. During the whole course the student has to deal with the content of the course. Figure 2 shows the general proceeding of a typical course week.

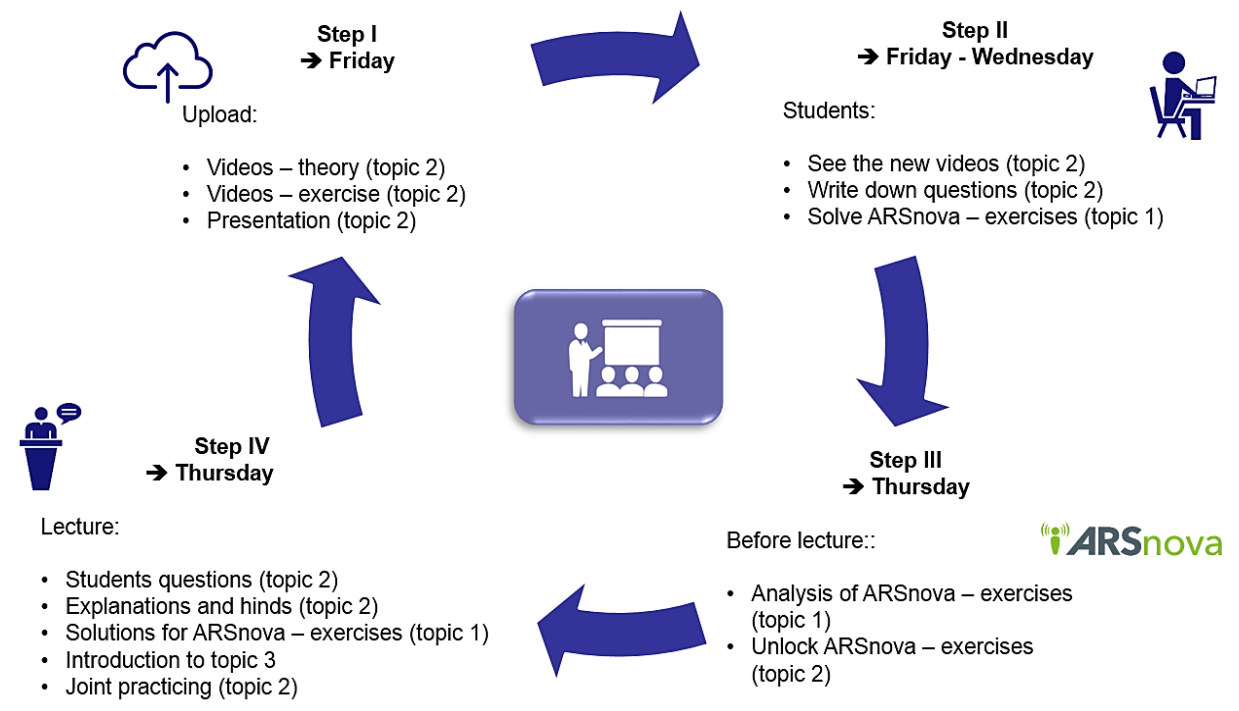

Figure 2. Typical course week. Source: authors

\section{Methodology}

The objective of this paper is to analyze the influence of the new developed flipped classroom concept on the student motivation.

\subsection{Sample and data collection process}

Sample of this paper are the students of the course introduction to management accounting at the HTW Berlin. The course consists of 14 - 16 lectures, depending on the semester. The students are usually in the $2^{\text {nd }}$ year of the bachelor study: business administration and engineering. The course is regularly separated into two groups of 40 students. This semester 102 students are registered in both courses. 65 students participated (64\% of the sample). A questionnaire was used to collect the data two weeks before the exam. The advantage of a questionnaire strategy is that it provides standardized answers that make it simple to compile data. Because the motivation topic is a very complex one, quantitative (4 point Likert scales) as well as qualitative data were collected to triangulate findings. The collected data were analyzed with the objective of establishing links between student motivation and the new concept. Furthermore the data were analyzed by SPSS and MS Excel. 


\subsection{Measures}

To test the influence of of the new developed flipped classroom concept on the student motivation the participants were asked regarding different topics (seperated into qualitative and quantitative clusters). The used items for the quantitative analysis were influenced by the work of Thielsch and Stegemöller (2014), Rheinberg et al. (2001), Wilkesmann et al. (2012) and Grötemeier and Thielsch (2014). The quantitative clusters were represented by the 3 following scales:

Motivation: Main objective of this scale is to find insights about the motivation of the students. A scale with 7 items was used to identify the overall motivation. A high value means that the students are motivated. The internal consistency of the scale is Alpha 0.91.

Concept: Within this scale it is important to find out how and to what extend the students accepted the new concept. A scale with 9 items was used to analyze the overall acceptance. A high value means that the participants are satisfied with the concept. The internal consistency of the scale is Alpha 0.85 .

Tools: This scale analyses how satisfied the students are with the different tools (theory and exercise videos, presentations and ARSnova). A scale with 16 items was used to analyze the quality of the tools, the usage behavior and the support feelings. A high value means that the students show a high acceptance. The internal consistency of the scale is Alpha 0.80 .

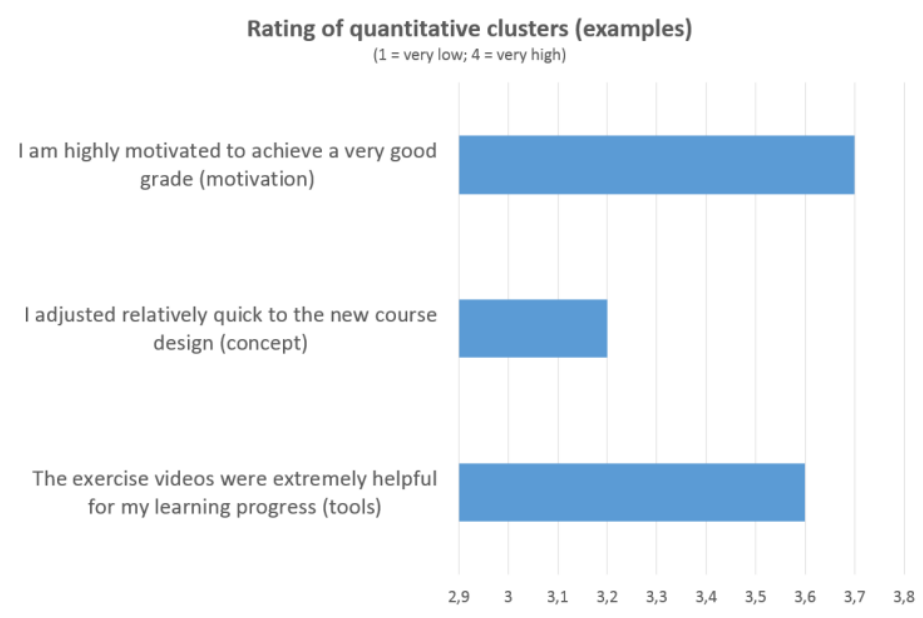

Figure 3. Examples of Likert-ratings for clusters. Source: authors 


\section{Findings}

The core topic of this paper is, if the new developed flipped classroom concept has an impact on student motivation. Therefore the mentioned scales in chapter 3.2 were analyzed with the help of a correlation analysis. Two significant inter-correlative connections can be detected. This includes the scales concept and motivation as well as motivation and tools. The results of this research support therefore the initial assumption: The new concept and the used tools have both a positive effect on student motivation.

Apart from the correlation analysis, some other questions can be answered. The comparison between different teaching concepts in Figure 3 shows a clear preference for flipped classroom lectures. This can be supported by some of the qualitative data. 18 Students (28\%) mentioned the good teaching style and the structure of the course. 23 Students (35\%) mentioned, that they are highly motivated because of the provided tools. Furthermore the students state that they like the possibility to see the videos again and again (28\%) and exercise whenever and wherever they want (14\%). This allows a continuous learning progress.

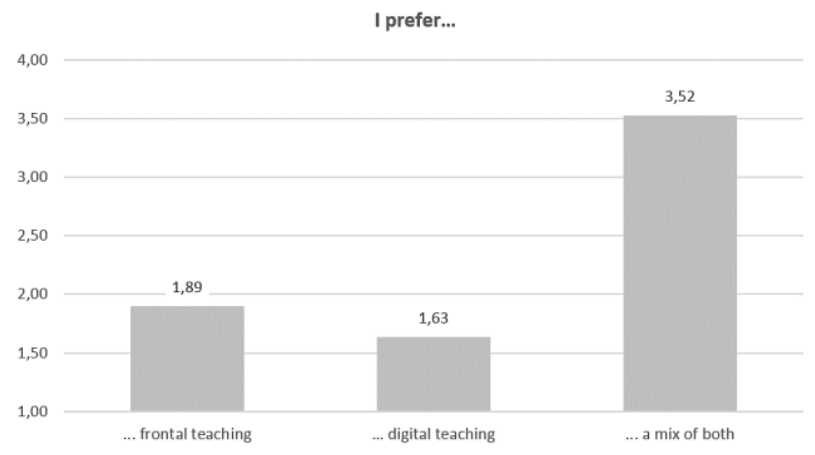

Figure 4. Different teaching concepts. Source: authors

\section{Discussion and Conclusions}

The findings emphasise the importance of a flipped classroom learning approach. The fact that students significantly prefer the combined teaching using both frontal lectures and digital tools versus only one teaching method indicates that the most effective learning takes place through combination. Classroom teaching has been the classical method of teaching for centuries and is the most applied form of teaching in many content and methodology-driven disciplines like management accounting. On the other hand, digital learning has been introduced already 25 years ago to external and management accounting and a diverse range of software-based learning tools have been developed since the early 1990 (Gabele et al. 1992). However, none of the digital tools have revolutionised the teaching methodologies and have prevailed as the single best methods. Students applying 
computer-based self-training tools need to maintain extremely high levels of motivation and self-discipline in order to complete the course. Moreover despite the fact that most selftraining tools offer the opportunity to control the learning progress, very few expose themselves to the constant monitoring and adjust their learning according to the self-test results. Without any external control mechanism motivation keeps decreasing and the learning success is in jeopardy. Observations from the class room confirm this assessment as students often feel challenged of even completing the theory and exercise videos. Only through motivation in the class room students feel encouraged to run through exercises and to recognise their individual learning progress. The use of a class response system has proven to be very effective. Students can individually work on exercises and control their knowledge and skills acquired so far. Furthermore, the instructors are able to identify significant learning and comprehension gaps and can react accordingly in the class room. It appears that the flipped classroom approach consisting of regular class room session combined with theory and exercise videos supported by a class response system turns out to be a very effective teaching concept. Certain improvement opportunities were identified by the instructors and confirmed by the students. One structural improvement related to the class organisation will ensure a better distribution of the workload over the entire semester. Students were collecting videos but were not effectively learning with them with the intent to internalise all content towards the end of the semester as part of their exams preparation. Due to the sheer amount of class materials this is an insurmountable tasks which will overstrain the knowledge absorption capacity. Therefore, the learning progress will be monitored at 4-6 milestones in form of short computer-based tests over the course of the 4month semester in order to ensure a more balanced learning. Another improvement opportunity is related to the plenitudes of materials as well. The learning density based on videos, exercises and class room training is extremely high and partly over exceeding the mental intake capacity. Partly this is even causing stress for the students. Consequently monthly recap sessions will be introduced to summarise and recess the content.

Even though the presented multi-method based flipped classroom concept has demonstrated high levels of effectiveness it will require further optimisations. Monitoring the knowledge absorption and the ability to transfer will be key to balance over and under challenging of students.

\section{References}

Deci, E. L. \& Ryan, R. M. (2000). The "What" and "Why" of Goal Pursuits: Human Needs and the Self-Determination of Behavior. Psychological Inquiry 11 (4), 227-268.

Dressler, S. \& Rachfall, T. (2012). Die Controllingweiterbildung der Zukunft. Zeitschrift für Controlling und Weiterbildung, No. 3, 209-213. 
Gabele, E. \& Fischer, P. \& Zuern, B. (1992). Kosten- und Erlösrechnung als interaktives Lernprogramm. Gowalla, U. \& Schopp, E. Hypertext und Multimedia: Neue Wege in der computerunterstützten Aus- und Weiterbildung. Berlin Heidelberg: Springer Verlag, 58-66.

Grötemeier, I., \& Thielsch, M. T. (2014). Münsteraner Fragebogen zur Evaluation Zusatzmodul Hausaufgaben (MFE-ZHa). doi: 10.6102/zis100.

Rheinberg, F.; Vollmeyer, R. \& Burns, B. D. (2001). FAM: Ein Fragebogen zur Erfassung aktueller Motivation in Lern- und Leistungssituationen. Diagnostica, 47, 57-66.

Schulmeister, R. (2015). Abwesenheit von Lehrveranstalungen. Hamburg, 2-57.

Schultz, E. (Ed.) (2014). The potential and problems of MOOCs - MOOCs in the context of digital teaching. Beiträge zur Hochschulpolitik 2/2014, 10-60.

Thielsch, M. T., \& Stegemöller, I. (2014). Münsteraner Fragebogen zur Evaluation Zusatzmodul computergestützte Lehre (MFE-ZcL). 10.6102/zis102.

Wilkesmann, U.; Fischer, H. \& Virgillito, A. (2012). Academic Motivation of Students The German Case. Discussion papers des Zentrums für HochschulBildung, 2-15. 